\section{A Nobel Prize for Dr. Irving Langmuir}

THE influence of the contributions to modern chemical thought of Dr. Irving Langmuir, who has been awarded the Nobel Prize for chemistry for 1932 , is probably more widespread and generally appreciated than those of many of his predecessors. It was as if a new chapter had been commenced in the book of knowledge of the state and behaviour of molecules at interfaces, which forms the very bases of the science of colloids and is of fundamental importance in such diverse ramifications of the physical sciences as heterogeneous catalysis and thermionic emission, when Langmuir published his well-known papers in 1917. As occasignally happens, mathematical treatment may obscure the reality of physical and chemical processes, and that useful tool may prove an obstruction rather than an aid to further advance. It is no exaggeration to say that a new flood of light was thrown on the whole subject of the adsorption of, and reactions of, gases at solid surfaces, as well as the mechanism involved in changes in the surface tension of liquids. There are no botter examples of the effects of welding our essentially chemical point of view, in which molecules are regarded as perfectly defined objects of definite form, with a physical appreciation of the general applicability of the 13oltzmann distribution law and of the action of local fiolds of force extending over relatively short distances. This same breadth of treatment is also noted in the more recent and what some may regard as more physical aspects of his work. Thanks to Langmuir, thermionies is now an important branch of physical chemistry.

IT is only natural that investigations of such a fundamental character should have economic conse. quences, and Langmuir's work has led to many important industrial results, of which the gas-filled lamp is probably most widely appreciated. What was once "Dr. Whitney's experiment" in the General Flectric Company has now become the life blood of all important industries, and it is a pity to note that apparently one large European firm is no longer encouraging fundamental research; probably the right men are not available. No small part of Langmuir's contributions to chemistry lies in his enthusiasm and the clarity of his presentation. The Lewis atom became as it were a household word when the concepts were developed, applied and expounded by Langmuir, and one almost had a vision of molecules of fatty acid floating across a water surface when listening to him. Those that know Langmuir as a friend aro always impressed both by his kindness and his great breadth of interests. Whether it is ice-skating in winter, observing the formation of ripples and surface currents in summer on Lake George, or noting the brilliance of spiders' eyes when illuminated by a flash-lamp, there is always something of interest, something arresting and something which would convince many a classical scholar of the great advantages of science as an educational medium.
Retirement of Prof. E. B. Poulton, F.R.S.

WhEN, now forty years ago, Prof. E. B. Poulton succeeded Prof. Westwood, its first holder, in the Hope professorship of zoology at Oxford, great antici. pations were entertained of the results to follow from the appointmont of one who had already distinguished himself as an able investigator and experimenter in the field of evolutionary study. These expectations have been abundantly fulfilled; and it is not too much to say that under Prof. Poulton's untiring exertions, the Hopo Department in the University of Oxford has become known throughout the scientific world as a chief centre for the maintenance and development of those views of organic evolution which owe their origin to the epochmaking work of Charles Darwin and Alfred Russel Wallace. Under his energetic administration, the great entomological collection, bequeathed by $\mathrm{Mr}$. Hope and tended in its early days by the first Hope professor, has been immensely increased, and has been made available in an unexampled manner for the illustration of problems of first-rate biological importance. By his influence in stimulating and directing the efforts of observers and collectors in many parts of the world, Prof. Poulton has been able to accumulate a vast amount of material of the highest value for scientific workers at home, to whom he has never failed to afford the utrnost help and encouragement. His own labours in tho field of bionomics have been far-reaching and fruitful, and have caused him to be known everywhere us tho most prominent living upholder of the doctrine of natural selection as propounded by Darwin in the "Origin of Species". His approaching retirement is felt, not only by entomologists, but also by the whole University of Oxford, as a serious loss; and it is much to be hoped that a successor may be found who will recognise and make it his business to carry on the great traditions of the Hope Department. It is a matter of congratulation that Prof. Poulton, when he relinquishes the engrossing task of administration, will be free to continue, on an even larger scale, those researches and expositions which havo had so remarkable an influence on the progress of scientific entomology.

\section{Dr. R. A. Millikan}

$I_{T}$ is stated by Science Service, of Washington, D.C., that a Roosevelt Medal for achievement in science has been presented to Dr. Robert Andrews Millikan, director of the Norman Bridge Laboratory of Physics and chairman of the executive council of the California Institute of Technology. The presentation was mado by James R. Garfield, Secretary of the Interior in the Roosevelt Cabinet. The medal is one of a series of awards established in 1923 by the Roosevelt Memorial Association. Usually three are given each year in three out of twelve fields of activity associatod with Col. Roosevelt's career, but only one award has been made in 1932. Dr. Millikan has become widely known because of his achievements in physical research and was awarded the Nobel Prize for physics in 1923. Outstanding among his 